\title{
HOSPITALIZAÇÃO POR TRANSTORNO BIPOLAR, CLIMA E ATIVIDADE SOLAR: ANÁLISE DE 36 ANOS DE REGISTROS
}

\begin{abstract}
Cleber de Souza Oliveira ${ }^{1}$ Maria Filomena Ceolim² ${ }^{1}$ Enfermeiro; Doutorando em Ciências da Saúde pela Faculdade de Enfermagem da UNICAMP ${ }^{2}$ Professora associada da Faculdade de Enfermagem da Universidade Estadual de Campinas
\end{abstract}

INTRODUÇÃO: O transtorno bipolar é uma condição grave de saúde caracterizada pela ocorrência de episódios de depressão, hipomania, mania ou quadros mistos com possível apresentação sazonal. OBJETIVO: Este estudo teve como objetivo analisar a distribuição temporal das hospitalizações de pacientes com transtorno bipolar associando-a com variáveis sóciodemográficas, clínicas, climáticas e astrofísicas. MÉTODO: Trata-se de um estudo descritivo, retrospectivo, transversal, documental e analítico. Foram analisados os dados dos indivíduos com transtorno bipolar no livro de registro de internações de um hospital psiquiátrico do interior do estado de São Paulo (Brasil) entre 01 de janeiro de 1980 e 31 de dezembro de 2015, totalizando 36 anos (432 meses). RESULTADOS: No período foram registradas 1933 hospitalizações por transtorno bipolar dentre um total de 37.151 hospitalizações na instituição. Encontrou-se associação significativa entre as estações do ano e número de internações por transtorno bipolar, em geral $(p=0,001)$, bem como para as internações por episódios maníaco $(p=0,009)$. Os episódios depressivos e por outros episódios não apresentaram associação significativa com as estações do ano. Observou-se, para todos os episódios, menor número de internações no verão, e aumento de internações por episódios de mania no inverno. Verificou-se também correlação significativa de baixa magnitude entre o número de internações por transtorno bipolar e variáveis astrofísicas, a saber: irradiância solar (coeficiente $R=-0,14$ ) e o número de manchas solares (coeficiente $R=-0,17$ ). CONCLUSÃO: O padrão de sazonalidade evidenciado neste estudo poderá contribuir para delineamento de estratégias de prevenção e melhoria do cuidado.

Palavras-chave: Transtorno bipolar. Hospitalização. Atividade solar. 